\title{
Abkürzungen und Abbildungen
}

Die Abkürzungen sind verwendet nach:

Der Neue Pauly (DNP). Enzyklopädie der Antike. Herausgegeben von Hubert Cancik und Helmuth Schneider, Bd. I, Stuttgart-Weimar 1996, XII-XLVII.

Abbildungen 1 und 2: Fotos Christian Kunze (Regensburg) 